\title{
A construção de saberes no desenvolvimento profissional docente: narrativas de professores do IFPI
}

\author{
The construction of knowledge in teacher professional \\ development: narratives of IFPI teachers
}

La construcción del conocimiento en el desarrollo profesional docente: narrativas de los profesores del IFPI EDILEUSA DE SOUZA SANTOS (iDa MARIA DIVINA FERREIRA LIMA (Db GUILHERME MENDES TOMAZ dOS SANTOS (D)

\section{Resumo}

O presente trabalho é parte de uma pesquisa concluída no Mestrado em Educação, tendo como objetivo compreender como se constroem os saberes docentes mobilizados na prática docente pelo professor de Educação Profissional e Tecnológica (EPT) no Instituto Federal de Educação, Ciência e Tecnologia do Piauí (IFPI). Trata-se de uma pesquisa de abordagem qualitativa, com adoção do método autobiográfico, utilizando-se de narrativas autobiográficas profissionais como técnica de produção de dados. Como campo empírico da pesquisa, delimitou-se o IFPI; e, como participantes, professores bacharéis e tecnólogos. Nessa perspectiva, empregaram-se como instrumentos de produção de dados quatro rodas de conversa e entrevista narrativa. O tratamento dos dados deu-se por meio da técnica de análise de conteúdo, na perspectiva de Bardin (2016), com o auxílio técnico do

\footnotetext{
a Instituto Federal de Educação, Ciência e Tecnologia do Piauí, Teresina, PI, Brasil. Mestra em Educação, e-mail: edileusa.souza@ifpi.edu.br

b Universidade Federal do Piauí, Teresina, PI, Brasil. Doutora em Educação, e-mail: lima.divina2@gmail.com

c Universidade Federal do Rio Grande do Norte, Natal, RN, Brasil. Doutor em Educação, e-mail: mendes.guilherme234@gmail.com
} 
software IRAMUTEQ. O estudo revelou que a principal ferramenta de construção dos saberes docentes ao longo da carreira dos professores bacharéis e tecnólogos da EPT é a experiência durante a prática docente. Os saberes docentes, com exceção dos saberes disciplinares, são construídos ao longo do desenvolvimento profissional docente, partindo, inicialmente, da concepção prévia sobre o que é ser professor, avançando para o aprendizado a partir da prática docente, assim como por meio das interações com os professores mais experientes e do contato com os alunos durante o processo educacional.

Palavras-chave: Saberes docentes. Desenvolvimento profissional docente. Educação Profissional e Tecnológica.

\section{Abstract}

The present work is part of a research completed in the Master in Education, with the objective to understand how to build the teacher's knowledge mobilized in teaching practice by the teacher of Professional and Technological Education (EPT) at the Federal Institute of Education, Science and Technology of the Piaui (IFPI). This is a research with a qualitative approach, with the adoption of the autobiographical method, using professional autobiographical narratives as a data production technique. As an empirical field of research, the IFPI was defined, and as participants, professors with bachelor's degree and technologists. In this perspective, four rounds of conversation and narrative interview were used as data production instruments. The data were processed using the content analysis technique, from the perspective of Bardin (2016), with the technical assistance of the IRAMUTEQ software. The study revealed that the main tool for the construction of teaching knowledge throughout the career of bachelor teachers and technologists at EPT is experience during teaching practice. Teaching knowledge, with the exception of disciplinary knowledge, is constructed throughout the professional development of teaching, starting, initially, from the previous conception of what it means to be a teacher, advancing to learning from teaching practice, as well as through interactions with the most experienced teachers and the contact with students during the educational process.

Keywords: Teaching knowledge. Teacher professional development. Professional and Technological Education.

\section{Resumen}

El presente trabajo es parte de una investigación realizada en la Maestría en Educación, con el objetivo de comprender cómo construir el conocimiento docente movilizado en la práctica docente por el docente de Educación Profesional y Tecnológica (EPT) del Instituto Federal de Educación, Ciencia y Tecnología de Piauí (IFPI). Se trata de una investigación con enfoque cualitativo, con la adopción del método autobiográfico, utilizando narrativas autobiográficas profesionales como técnica de producción de datos. Como 
campo empírico de investigación se eligió el IFPI, y como participantes, profesores de licenciatura y tecnólogos. En esta perspectiva, se utilizaron cuatro rondas de conversación y entrevista narrativa como instrumentos de producción de datos. Los datos fueron procesados mediante la técnica de análisis de contenido, desde la perspectiva de Bardin (2016), con la asistencia técnica del software IRAMUTEQ. El estudio reveló que la principal herramienta para la construcción del conocimiento docente a lo largo de la carrera de los docentes y tecnólogos de la EPT es la experiencia durante la práctica docente. El conocimiento docente, con excepción del conocimiento disciplinar, se construye a lo largo del desarrollo profesional del docente, partiendo, inicialmente, de la concepción previa de lo que significa ser docente, avanzando hacia el aprendizaje desde la práctica docente, así como a través de interacciones con el profesorado los profesores más experimentados y el contacto con los alumnos durante el proceso educativo.

Palabras clave: Conocimiento docente. Desarrollo profesional docente. Educación Profesional y Tecnológica.

\section{Introdução}

O presente trabalho, resultante de uma pesquisa concluída de mestrado, aborda a construção de saberes docentes no processo de desenvolvimento profissional de professores bacharéis e tecnólogos que lecionam na Rede Federal de EPT, tomando como campo empírico o IFPI, que é uma instituição centenária, com uma histórica experiência no ensino técnico e tecnológico. A partir da Lei $n^{\circ}$ 11.892/20081, a instituição ampliou sua função social, passando a atuar no âmbito da educação básica, profissional e superior, participando de um intenso processo de expansão e interiorização da referida rede (BRASIL, 2008).

A EPT abrange a participação de profissionais com conhecimentos específicos em diversas áreas do conhecimento, tais como engenharia, tecnologia da informação, administração, entre outras. Em sua grande maioria, os docentes dos cursos técnicos e tecnológicos são bacharéis ou tecnólogos. Muitos deles tornaram-se professores da EPT sem possuir formação para a docência, porquanto além das especificidades e singularidades dessa modalidade, em que a realidade pedagógica se relaciona com a tecnológica, a ausência de exigência legal de formação de professores é outro fator determinante para essa conjuntura.

\footnotetext{
${ }_{1}^{1}$ Recuperado de http://www.planalto.gov.br/ccivil_03/_ato2007-2010/2008/lei//11892.htm 
De acordo com Ramirez (2011), a constituição de professores oriundos dos cursos de bacharelado dá-se, geralmente, por meio da experiência prática vivida ao longo de sua trajetória profissional no contexto educacional.

Considerando o pressuposto de que os conhecimentos trazidos da formação inicial pelos bacharéis e tecnólogos não estão relacionados ao exercício da profissão professor, compreende-se que o contexto do magistério na EPT traz ao docente, em especial no início da carreira, desafios relacionados ao exercício profissional, principalmente àqueles que não contam com formação pedagógica capaz de subsidiar a sua prática (PORTELA, 2017).

Para a autora supracitada, embora todo professor dessa modalidade de ensino possua conhecimento para o desenvolvimento de uma atividade profissional, ele não está relacionado diretamente ao exercício profissional da profissão docente.

Diante desse contexto, concebe-se necessário refletir sobre a complexidade do trabalho docente, uma vez que a pluralidade do saber pedagógico torna esse labor desafiador. O saber docente está sempre em movimento, pois, como ser social, o professor traz consigo uma bagagem composta por sua formação inicial, aliada à sua história individual e sociocultural (NUNES, 2016).

Toda essa bagagem pessoal e profissional, atrelada à realidade encontrada no contexto escolar, assim como às interações com a comunidade escolar e a outros aspectos do desenvolvimento profissional docente, pode repercutir em novos saberes, gerados durante a atividade docente.

Partindo dessa lógica, o presente trabalho parte da seguinte questão-problema: como, no exercício da docência, o professor sem formação pedagógica constrói saberes que contribuem para a sua prática docente na EPT do IFPI?

Em face da necessidade de discutir tais aspectos, o estudo objetivou compreender de que modo são construídos os saberes docentes mobilizados na prática docente pelo professor de EPT no IFPI. 


\section{Os saberes docentes na atuação do professor de EPT: alguns apontamentos teóricos}

A ação do professor vem sendo motivo de muitas pesquisas nas últimas décadas, tendo os saberes e práticas docentes como referência para subsidiar as discussões no contexto educacional (GAUTHIER et al., 2006; PIMENTA, 2012; TARDIF, 2014).

Os saberes docentes têm um caráter subjetivo e, por vezes, assumem formas diferenciadas e requerem reflexões acerca de sua construção por parte dos professores (GONÇALVES, 2016). Nesse contexto, durante a sua trajetória, esse profissional constrói e reconstrói seus saberes de acordo com suas experiências, seu itinerário formativo e de acordo com a necessidade de utilização desses elementos (NUNES, 2001).

O interesse dos pesquisadores pelo tema dos saberes surgiu em nível internacional nas décadas de 1980 e 1990, motivado pela busca de legitimidade da profissão docente e de um conjunto de conhecimentos que caracterizassem essa categoria profissional. As pesquisas com foco nos saberes dos professores foram fortemente influenciadas pelos estudos sobre a epistemologia da prática profissional desenvolvidos por Schön (2000).

Partindo dos conceitos desenvolvidos pelo susodito teórico sobre o conhecimento na ação, alavancaram-se os estudos sobre os processos de pensamento utilizados pelos professores. Por conseguinte, as concepções atinentes ao conhecimento na ação trouxeram grande crítica à racionalidade técnica, que tende a limitar o trabalho docente a modelos teóricos desvinculados da realidade concreta.

Por seu turno, as pesquisas de Shulman (1986) investigam os diversos tipos e as modalidades de conhecimento que os professores detêm, caracterizando uma epistemologia própria. A partir dos estudos sobre os saberes dos professores a respeito dos conteúdos que ensinam, o autor apresenta um modelo com os componentes da base de conhecimento profissional para o ensino.

Ademais, o supracitado estudioso aponta que, ao tomar decisões sobre suas aulas, os professores lançam mão de diversos tipos de conhecimentos, dentre eles: conhecimento de conteúdo específico; conhecimento pedagógico geral; 
conhecimento pedagógico do conteúdo; conhecimentos dos alunos e de suas características; conhecimento do currículo; conhecimento dos fins e das metas da educação, e dos contextos educacionais.

Nesta investigação, parte-se da premissa de que os professores bacharéis e tecnólogos, quando chegam à docência na EPT, trazem consigo o domínio de seu campo específico de conhecimentos, tendo em vista a formação inicial em sua área, suas pós-graduações e as experiências adquiridas na busca por titulações acadêmicas.

Pode-se dizer que o professor da EPT possui o conhecimento, denominado por Shulman (1986) de conteúdo específico. Assim sendo, se por um lado, tem-se a confirmação dos conhecimentos técnicos dos conteúdos do curso, tendo em vista que fundamentados em suas práticas, podem lançar mão deles, “extraídos de sua profissão e articulá-los com as teorias estudadas, por outro lado, faltam-lhes conhecimentos pedagógicos ou do fazer pedagógico” (PORTELA; CARVALHÊDO, 2017, p. 231).

Com esse entendimento, defende-se que a docência requer, além de conhecimento de conteúdo específico, o saber pedagógico, que alude aos conhecimentos pedagógicos necessários à transformação do conteúdo a ser ensinado em conteúdo a ser aprendido. Decerto, não se quer dizer que esses tipos de saberes são os únicos necessários ao professor, nem mesmo suficientes para garantir um bom ensino. Desse modo, a discussão prossegue revelando a pluralidade dos saberes docentes à luz de diversos teóricos.

No cenário das pesquisas educacionais brasileiras, o tema surge de forma discreta a partir da década de 1990. A propósito, Nunes (2001) esclarece que, nessa época, as investigações sobre formação de professores interessavam-se em analisar a prática pedagógica e os saberes docentes a partir de um resgate acerca do papel do professor, de modo que ele tenha uma formação para além do conhecimento meramente acadêmico, envolvendo o desenvolvimento pessoal, profissional e organizacional da profissão docente.

Com o desenvolvimento das pesquisas de abordagem (auto)biográficas, as histórias de vida dos professores tornam-se foco central das reflexões, passando a reconhecer os saberes construídos pelos professores como legítimos. Sobre esse período, Pimenta (2012) aduz que era necessário repensar a formação inicial e contínua partindo da análise das práticas pedagógicas e docentes. Esse novo olhar 
para a prática docente fomentou uma diversidade de estudos sobre os saberes docentes, com vistas a identificar os diferentes saberes contidos na prática dos professores.

Esse movimento apresenta-se como novo paradigma na formação de professores, defendendo que é preciso considerar o professor em sua própria formação, com a capacidade de reelaborar seus saberes iniciais durante $o$ enfrentamento de sua prática, constituindo-os a partir de uma reflexão na e sobre a prática (NUNES, 2001).

Trata-se, pois, da indicação de uma formação docente a partir do olhar dos próprios professores envolvidos. A partir dessa nova abordagem, o professor é considerado como um profissional que adquire e produz conhecimentos a partir da prática, assim como do enfretamento das condições de trabalho.

Nesse sentido, Gonçalves (2016) afirma que, o saber docente está atrelado à mobilização de diversos conhecimentos articulados pelo professor no contexto educacional, vinculado a um saber ou um conjunto de saberes relacionado com a sua identidade, suas experiências de vida, sua trajetória profissional e suas relações no espaço escolar. Para a referida autora, o saber do professor constrói-se no exercício profissional, nomeadamente no contexto áulico e, à medida que se vai construindo a prática, emergem novos conhecimentos que se agregam e se transformam em saberes docentes.

Por esse ângulo, Tardif e Lessard (2012) trazem o conceito do que é o "saber". Eles defendem que saber qualquer coisa ou fazer qualquer coisa de forma racional é ser capaz de responder às questões seguintes, demonstrando fundamentos e razões capazes de validar o discurso ou a ação: por que você fez isso? Por que você diz isso?

Para os referidos autores, não basta fazer algo, ainda que bem: é necessário que o professor saiba por que faz as coisas de determinada forma. Os teóricos trazem esse questionamento com o intuito de evitar que as pesquisas sobre os saberes docentes sofram o que eles chamam de "excesso etnográfico", ou seja, em que tudo é considerado como saber: ideologias, crenças, emoções, intuição e rotinas. À vista disso, questionam: se tudo é saber, para que então estudar o saber? Dessa forma, consideram como saberes docentes todos os atos e discursos por meio dos quais os professores são capazes de fornecer razões, visando a justificá-los. 
Destarte, neste estudo, reputa-se a noção de saber no sentido apresentado por Tardif (2014, p. 60), ou seja, como um "conjunto de saberes que fundamentam o ato de ensinar no ambiente escolar" proveniente de fontes diversas. Concebe-se um sentido amplo, uma vez que abrange os conhecimentos, as capacidades, as habilidades (ou aptidões) e as atitudes dos professores, isto é, aquilo que muitas vezes é chamado de saber, saber fazer e saber ser.

Para Tardif (2014), os saberes que integram a prática do professor se classificam em quatro tipos: da formação profissional, que são os saberes baseados nas ciências, nos saberes trabalhados pelas instituições de formação de professores; os disciplinares, administrados e transmitidos pela comunidade científica, nos cursos e departamentos universitários; os curriculares, que correspondem aos discursos, objetivos, conteúdos e métodos; e experienciais, resultantes do exercício da atividade profissional dos professores.

Para o supracitado teórico, o saber de um professor é plural e heterogêneo, resultante de uma realidade social composta por intermédio de elementos como formação, programas, práticas coletivas, disciplinas escolares, assim como de uma pedagogia institucionalizada, e é, ao mesmo tempo, um saber próprio, que se constitui mediante suas experiências de vida e sua carreira profissional, em suas relações com os alunos em sala de aula e outras relações com a comunidade escolar.

À vista disso, Gonçalves (2016) defende que, pensar em exercício da docência é pensar, também, em formação do professor. Aliás, para a autora, os saberes construídos e mobilizados suscitam reconhecer a existência de uma base de conhecimentos para o ensino da profissão. Logo, os saberes docentes vão-se estabelecendo a partir de uma reflexão na e sobre a prática, o que resulta dizer que a relação dos docentes com os saberes extrapola a função de transmissão do conhecimento.

Neste ínterim, de acordo com Portela (2017), os saberes são construídos pelo professor bacharel à medida que o seu desenvolvimento profissional contempla os espaços formativos oportunizados ao longo dos anos. Segundo a autora, ao ingressarem no magistério, é provável que os professores exponham necessidades formativas distintas dos saberes inerentes à sua área de atuação profissional, reconhecendo a existência de saberes além dos relacionados aos conteúdos que ensinam. 


\section{Dispositivo metodológico}

Este estudo trata-se de uma pesquisa de abordagem qualitativa, com adoção do método autobiográfico (NÓVOA; FINGER, 2010), tendo as narrativas autobiográficas profissionais como técnica de produção de dados (CLANDININ; CONNELLY, 2015). O campo empírico foi o IFPI; e os participantes da pesquisa, sete professores lotados em cinco campi diferentes, quais sejam: Campo Maior, Dirceu Arcoverde, Piripiri, Teresina Central e Teresina Zona Sul.

Os professores selecionados estão em uma faixa etária diversificada, entre 29 e 65 anos. Possuem formação inicial em bacharelado ou tecnólogo, sendo dois Bacharéis em Administração, um Bacharel em Ciências da Computação, um Bacharel em Engenharia Civil, um Tecnólogo em Processamento de Dados, um Tecnólogo em Análise e Desenvolvimento de Sistemas, e um Tecnólogo em Design de Moda.

No tocante à experiência docente dos participantes, o tempo de exercício no IFPI varia de 4 e 24 anos de carreira. Com o intuito de garantir o anonimato, os colaboradores foram identificados pelos codinomes Festa, Vida, Canção, Força, Fé, Semente e Luz:

Como instrumentos de produção de dados, adotaram-se quatro rodas de conversa (WARSCHAUER, 1993) e entrevista narrativa (JOVCHELOVITCH; BAUER, 2015). A escolha das narrativas autobiográficas como técnica de produção de dados deu-se pelo entendimento de que elas permitem conhecer a trajetória profissional dos participantes por meio das histórias narradas, levando à compreensão sobre os saberes produzidos pelos professores ao longo da carreira e como tais saberes contribuem para a ressignificação das práticas docentes.

A roda de conversa corresponde a uma metodologia participativa em que é possível dialogar com os sujeitos. Nesse sentido, parte-se da concepção de roda apresentada por Warschauer (1993), que propõe reunir pessoas com histórias de vida diversas, suas próprias maneiras de pensar e sentir, a fim de estabelecer diálogos durante os encontros.

Para o tratamento dos dados, partiu-se da técnica de análise de conteúdo, na perspectiva de Bardin (2016). Com esse propósito, percorreram-se as três fases elencadas pela autora, a saber: a pré-análise, seguida da exploração do material e, por 
último, o tratamento dos resultados, a inferência e a interpretação, que se concretiza na definição das categorias da análise, visando à construção do corpus das narrativas, a partir das questões norteadoras do estudo, e no desnudamento dos conteúdos implícitos nos relatos.

Quanto à análise dos dados, recorreu-se ao software Interface de $\mathrm{R}$ pour les Analyses Multidimensionnelles de Textes et de Questionnaires (IRAMUTEQ) como ferramenta de processamento de dados na pesquisa qualitativa, por meio da análise de Classificação Hierárquica Descendente (CHD). ${ }^{2}$

A opção por trabalhar com o auxílio do software fundamentou-se na necessidade de reconhecer as vantagens que ele garante ao processo de análise dos dados, no que tange ao auxílio na organização e separação de informações com maior eficiência, à facilidade na localização dos segmentos de texto, além de agilidade no processo de codificação, se comparado ao realizado manualmente (CRESWELL; CLARK, 2013).

\section{Resultados e discussão}

Durante a produção de dados, os professores narraram suas trajetórias profissionais, destacando como se tornaram professores e como se deu o seu desenvolvimento profissional ao longo da carreira docente. A Figura 1 representa uma nuvem com as palavras mais evocadas pelos professores em relação ao desenvolvimento profissional docente, constituída a partir da frequência de palavras do corpus textual.

\footnotetext{
$2 \mathrm{Na}$ análise de classificação hierárquica descendente, os segmentos de texto são classificados de acordo com seus respectivos vocabulários e conforme a frequência das formas reduzidas. Essa interface proporciona a recuperação dos segmentos de textos e a associação de cada um em categorias, permitindo o agrupamento das palavras estatisticamente significativas para a pesquisa.
} 
Figura 1 - Nuvem de palavras mais mencionadas pelos professores

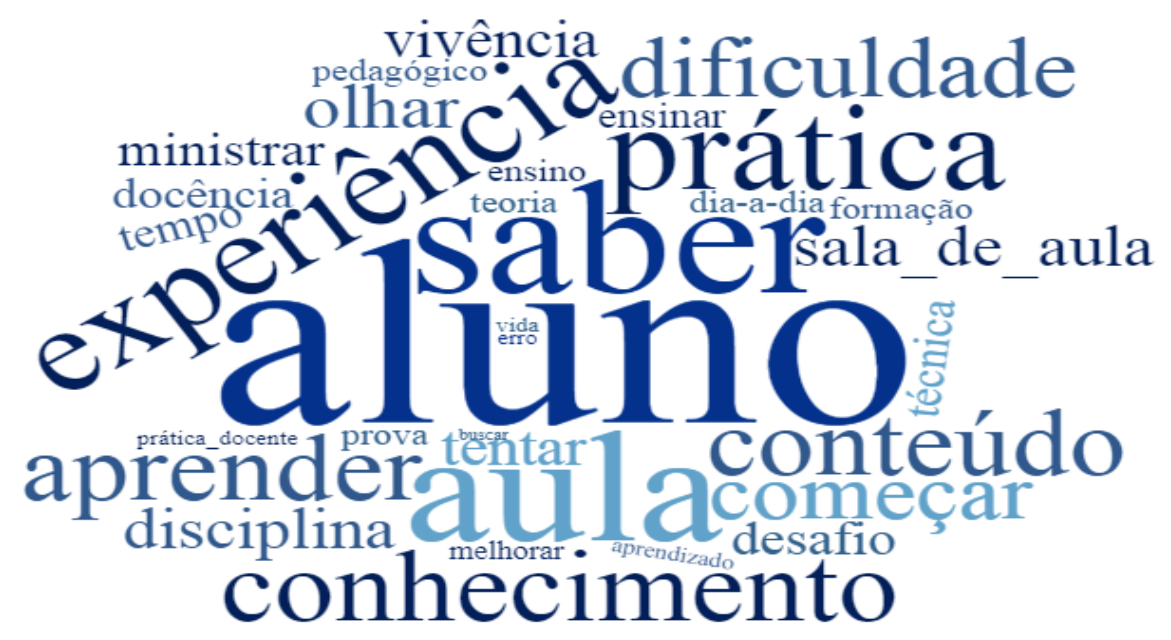

Fonte: Gerado pelo software IRAMUTEC, com base nos dados empíricos (2020).

Examinando a Figura 1, deduz-se que as palavras mais indicadas fazem referência à construção do saber docente no exercício da docência. Nesse tipo de análise, as palavras aparecem em tamanhos distintos, pois variam de acordo com o número de ocorrências no corpus. No Quadro 1, a seguir, elenca-se o grupo de termos mais citados, daí porque aparecem em destaque na nuvem, seguidos do número de ocorrência nas narrativas.

Quadro 1 - Ocorrência de termos mais evocados nas narrativas

\begin{tabular}{|l|l|l|l|}
\hline Termos evocados & $\begin{array}{l}\text { Número de } \\
\text { ocorrências }\end{array}$ & Termos evocados & $\begin{array}{l}\text { Número de } \\
\text { ocorrências }\end{array}$ \\
\hline Aluno & 50 & Docência & 08 \\
\hline Saber & 31 & Técnica & 08 \\
\hline Aula & 30 & Tempo & 08 \\
\hline Experiência & 23 & Ensinar & 07 \\
\hline Prática & 23 & Pedagógico & 06 \\
\hline Conhecimento & 19 & Dia a dia & 06 \\
\hline Conteúdo & 18 & Formação & 06 \\
\hline Aprender & 16 & Teoria & 06 \\
\hline Começar & 15 & Ensino & 06 \\
\hline Olhar & 12 & Prova & 06 \\
\hline Disciplina & 11 & Melhorar & 05 \\
\hline Sala de aula & 11 & Prática docente & 04 \\
\hline Vivência & 10 & Aprendizado & 04 \\
\hline Tentar & 10 & Erro & 04 \\
\hline Ministrar & 09 & Vida & 04 \\
\hline Desafio & 09 & Buscar & 03 \\
\hline
\end{tabular}

Fonte: Elaborado a partir do levantamento feito pelo software IRAMUTEC, com base em dados empíricos (2020). 
As palavras apresentadas na nuvem e no Quadro 1 são elementos constitutivos das representações dos professores acerca do processo de desenvolvimento profissional no qual os saberes docentes são construídos, alvo de análise nos tópicos seguintes. A partir da análise da ocorrência das palavras e dos segmentos de texto aos quais estão ligadas, chegou-se à definição de três indicadores de análise da pesquisa. Não obstante, para os fins deste artigo, discute-se apenas o indicador que diz respeito à construção do saber docente na EPT.

Ao analisar as narrativas dos professores, busca-se responder à questão norteadora do trabalho: como, no exercício da docência, o professor sem formação pedagógica constrói saberes docentes que contribuem para a sua prática na EPT do IFPI? Nesse sentido, durante esta discussão, avança-se nos apontamentos sobre os saberes da docência na EPT, com vistas a esclarecer como eles são apreendidos, mobilizados e valorizados na carreira dos professores pesquisados.

Observa-se que dentre as palavras recorrentes no corpus da pesquisa, o termo experiência ocorreu 23 vezes, sendo a quarta palavra (formes actives) mais citada pelos interlocutores nessa categoria. Nesse momento, é pertinente relembrar que os saberes experienciais (TARDIF, 2014) defendidos nesta pesquisa têm origem na própria prática cotidiana dos professores, em confronto com as condições da profissão, e implicam um professor ativo capaz de superar a experiência imediata que, continuadamente, constitui e reconstitui esse saber pela reflexão da própria prática.

Resta, ainda, antes da discussão principal, ressaltar que os interlocutores deste estudo já contam com, pelo menos, quatro anos de carreira docente na EPT e, em vista disso, foram capazes de elencar, em suas narrativas, elementos que deram sustentação às discussões sobre os saberes docentes.

De acordo com Tardif (2014), após os três primeiros anos da carreira docente, o professor é capaz de refletir mais acerca de seu trabalho, de modo a promover uma autorreflexão sobre seu próprio exercício profissional, identificando as (in)tensões sobre os diferentes aspectos vivenciados em seu cotidiano laboral.

A partir dessas considerações, examinam-se os trechos narrativos nos quais se destaca a experiência, como mostra o Quadro 2. 
Quadro 2 - A experiência acadêmica como ponto de partida para a prática docente

Eu olhava para o que eu tinha vivido com os meus professores e tentava, baseada na experiência, visualizar os meus professores que eu tinha tido, que eu poderia ser uma professora mais ou menos daquele jeito. E eu me espelhava com essa vivência porque eu não tinha nenhuma prática docente, não tinha nenhum conhecimento pedagógico. Eu ficava lembrando das minhas aulas: como o professor se comportava, como o professor reagia, como o professor direcionava os momentos da aula, pra eu poder direcionar aquilo ali. Eu não tinha nenhuma noção de teoria e como desenvolver ali. Eu só sabia que tinha que compartilhar aquele conteúdo. Estudar e preparar aquela aula. Preparar as avaliações e tudo mais. (FÉ, DOCENTE DO IFPI).

Como eu não tinha nenhuma prática docente, a minha experiência era pegar o que aprendi com meus professores. Tudo aquilo que eu via como exemplo dos meus professores, eu passei a passar pros meus alunos. (FORÇA, DOCENTE DO IFPI).

Fonte: Dados da pesquisa (2020).

Os participantes Fé e Força iniciaram suas carreiras docentes no IFPI. Atualmente, ambos têm, aproximadamente, seis anos de carreira docente. Os dois professores referem-se às suas primeiras atividades na docência demonstrando que o ponto de referência inicial foram suas experiências como alunos. Percebe-se que os interlocutores já detinham um saber prévio sobre o que é ser professor, proveniente de sua vivência como estudante durante a sua história de vida escolar.

Segundo Pimenta (2012), essa experiência faculta dizer quais foram bons professores com relação a aspectos como conteúdos, metodologias, avaliações, ou seja, quais sabiam ensinar e quais foram significativos em suas vidas, contribuindo para a sua formação. Assim, no início da carreira, boa parte do que os professores sabem sobre o ensino, sobre o papel do professor e sobre como ensinar, decorre das experiências enquanto discente, refletindo em suas crenças e representações sobre a prática docente.

A entrada na carreira, em consonância com Huberman (1995), é marcada pelo aspecto da "sobrevivência" e da "descoberta". Aquela relaciona-se ao "choque com a realidade", em que a confrontação com a realidade profissional e com o desafio das situações que marcam o exercício da docência são aspectos marcantes da iniciação profissional docente. Já o aspecto da "descoberta" se faz presente por meio da experimentação e da responsabilidade de ter de conduzir o processo educacional dos alunos. 
Frente ao exposto, salienta-se que as narrativas demonstram que a influência de elementos da experiência adquirida enquanto estudantes, não necessariamente a mais recente, mas as mais significativas, norteiam os professores iniciantes para agirem como agem e tomarem as decisões que tomam nos primeiros contatos com a docência, seja no planejamento ou na condução de suas aulas.

No decorrer das narrativas, pode-se mencionar que com o passar do tempo, a prática constitui-se como lugar onde se aprendem, constroem-se e validam-se os saberes da profissão. Os estudos de Tardif (2014) e Gauthier et al. (2006) ressaltam a relevância dos saberes da experiência como elemento fundamental na realização da prática docente. Nas falas seguintes, presentes no Quadro 3, é possível observar a valorização da experiência apontada pelos professores.

\section{Quadro 3 - Narrativas sobre a valorização da experiência}

E assim, errando, eu passei a não trabalhar apenas só com provas escritas, eu já fazia seminário também, depois uma avaliação escrita. Eu começo a planejar como é que vai ser o desenvolvimento da disciplina. E a gente vai se construindo, vai aprendendo esses "comos" ao longo da prática mesmo. Com as experiências que eu vivia com o que eu percebia ali das rotinas de sala de aula, eu ia me formando, eu ia me tornando professora. Você vai errando para aprender. (FÉ, DOCENTE DO IFPI).

Eu tive que aprender. Foi meio que tentativa e erro. Eu tentava, errava, aí depois tentava refazer novamente prática, seja por meio de dinâmicas, seja por meio de prática de laboratórios. Foi uma tentativa e erro. Sempre foi tentativa e erro. E outra coisa que eu procurei ter aprendizado foi pesquisando, mesmo, na internet sobre isso, sobre prática docente. Eu assistia videoaulas onde aprendia. Eu aprendia como os professores passavam aquele conteúdo que era técnico. Como eu conseguiria passar aquele conteúdo técnico usando os recursos didáticos adequados? É uma coisa que eu sou carente, porque o meu aprendizado ele vem mais da experiência, da minha experiência e da experiência dos outros colegas. (FORÇA, DOCENTE DO IFPI).

A gente vai aprendendo com os acertos e erros. Então isso aí a gente vai aprendendo, na prática, uma forma de que eles se interessem. Foi só a experiência mesmo. Tinha que fazer mesmo. Botar a cara. (LUZ, DOCENTE DO IFPI).

A gente vai vendo o quê que funciona e o quê que não funciona, e a gente vai se reinventando. É a prática do dia a dia, a vivência. Depois de um tempo a gente vai tendo prática e pegando os macetes. (VIDA, DOCENTE DO IFPI). 
Quadro 3 - Narrativas sobre a valorização da experiência

(conclusão)

E o dia a dia é claro. Por isso eu digo da vivência, a importância da vivência do dia a dia. Então eu digo que é uma construção, desconstrução e uma construção, e é todo dia. Coisa que em livro não Ihe oferece. Mas no dia a dia é que é. Então o Instituto me ensinou isso: a vivência. (SEMENTE, DOCENTE DO IFPI).

Aí era observando os meus erros, observando aquilo que eu tinha que melhorar. E fui crescendo. Só vivendo, não tem outro jeito. Não tem. Porque é exatamente a prática. Então se você começar a fazer aquele bolo todo dia, todo dia, aí sim, aí você vai. Na teoria é uma coisa, mas quando você vai ver a receita na sala de aula, você vai ver como não são as mesmas medidas. Você vai adaptando. (CANÇÃO, DOCENTE DO IFPI).

Os erros, principalmente. E, principalmente, entender que eram erros, como eu estou dizendo, erros de didática. Eu acho que a didática foi a grande vilã da minha vida docente. Exatamente em não perceber nos momentos certos os públicos que eu estava trabalhando, por não ter formação, talvez, talvez. (FESTA, DOCENTE DO IFPI).

Fonte: Dados da pesquisa (2020).

Analisando os trechos narrados no Quadro 3, nos quais a experiência aparece explicitamente ou contida no conteúdo da mensagem, assimila-se que a principal fonte para a construção dos saberes docentes, apontada pelos participantes da pesquisa, especialmente no início da carreira, tem relação com a experiência da prática de ensino em sala de aula, sobretudo no contato com os alunos e no esforço de transformar o conhecimento tecnológico em saber escolar, pronto a ser ensinado e aprendido pelos discentes (GARIGLIO; BURNIER, 2014). O valor do aprendizado da docência, por meio da prática, conforme atribuído pelos professores, aparece em segmentos narrativos representados por palavras e expressões recorrentes, a exemplo de: experiência, vivência, dia a dia, tentativa e erro.

Os depoimentos evidenciaram que a aprendizagem inicial do exercício da docência ocorreu de forma experimental e processual. Ambos utilizaram as ideias "tentativas", "acertos" e "erros" para patentear que a aprendizagem profissional se deu na continuidade da prática.

Sobre esse aprendizado, Tardif (2014, p. 108) esclarece que

Esse aprendizado, muitas vezes difícil e ligado à fase de sobrevivência profissional, na qual o professor deve mostrar que é capaz, leva à construção dos saberes experienciais que se transformam muito cedo em certezas profissionais, em truques 
do ofício, em rotinas, em modelos de gestão de classe e de transmissão da matéria. Esses repertórios de competências constituem o alicerce sobre o qual vão ser edificados os saberes profissionais durante o resto da carreira.

A assertiva do referido autor encontra eco no relato dos professores investigados nesta pesquisa. É possível visualizar a semelhança entre a ideia do autor e dos participantes, quando se observa o que Vida diz no trecho: "Depois de um tempo a gente vai tendo prática e pegando os macetes". A frase denota a ideia de "sobrevivência profissional", em que o professor busca, de forma autônoma, aprender a partir da prática, e essa aprendizagem empírica inicial servirá de base para a construção dos saberes no decorrer da trajetória profissional.

Pelo conteúdo das narrativas demonstradas no Quadro 3, foi possível observar que os professores traziam consigo a preocupação em desenvolver os saberes pedagógicos, nomeadamente no que se refere à gestão da sala de aula, ao planejamento, à construção de metodologias de ensino e de material didático para as disciplinas lecionadas.

Quando questionados como constroem os saberes docentes mobilizados na prática docente, os participantes destacaram, principalmente, aspectos voltados ao saber-fazer. $\mathrm{Na}$ fala de Fé, nota-se que o "tornar-se professora" está ligado à aprendizagem dos "comos", que diz respeito aos diversos aspectos da atuação docente como, por exemplo, planejamento, metodologias de ensino e avaliação da aprendizagem, que a própria participante menciona em sua fala.

Os discursos dos depoentes não deixam de pontuar que a docência na EPT demanda, além de conhecimento tecnológico e experiência no mercado de trabalho, um grupo de habilidades pedagógicas que seriam específicas ao exercício dessa prática profissional: planejar aulas; preparar recursos didáticos; avaliar a aprendizagem dos estudantes; desenvolver e avaliar projetos; motivar os alunos; mediar conflitos e assegurar a disciplina em sala de aula; comunicar-se adequadamente, de acordo com o nível da turma. Para a execução dessas tarefas, os docentes necessitam intensamente de saberes que tragam sentido, coerência e unidade ao fazer pedagógico no espaço escolar.

Cada um à sua maneira, e expressando marcas do contexto em que trabalham, os docentes pesquisados demonstraram reconhecer a necessidade de dominarem um repertório de conhecimentos e habilidades pedagógicas inatos a essa profissão. 
Outro espaço para a construção de saberes da docência, revelado nas falas dos interlocutores, diz respeito à relação de troca de conhecimentos com os professores mais experientes e por meio do contato com os alunos durante o processo educacional, como se expõe no Quadro 4.

Quadro 4 - A interação com professores mais experientes e com os alunos como contributo para aprendizagem profissional

Então eu fui unindo tudo aquilo que eu estava vivendo, e foi como se fosse assim um quebracabeça, [...] sempre observando como os professores iam conduzindo, como eles se portavam, e tudo. E a experiência também, digamos assim. A conversa com os demais professores nesses cursos, porque todos eram professores experientes. O feedback com os alunos, isso também é interessante. Eu me percebia, meu comportamento, via o que as pessoas comentavam e ia tentando a partir daí. Se eu estava muito rígida, o que eu podia ceder mais, ser mais criativa. O que eu preciso melhorar. (CANÇÃO, DOCENTE DO IFPI).

Quando eu comecei não tinha nem experiência de nada, nem como fazer uma prova, não sabia como preencher o diário. Quando eu entrei também não houve capacitação para nós enquanto a isso. Então foi mais explorando, por contato com os próprios colegas que já tinha uma experiência. Então meu aprendizado veio da experiência dos próprios colegas. Mas tudo isso foi ao longo de vários anos testando essas ferramentas. Aprendendo com os colegas, com as ferramentas que eu utilizava e aprendendo na internet com outros profissionais. (FORÇA, DOCENTE DO IFPI).

A gente está sempre conversando e trocando ideias. Se eu tenho algum problema com uma turma, se houve algum problema com um aluno, a gente sempre está fazendo esse momento de troca. E eu acho muito importante. Acho que no momento de troca você aprende também com a experiência do colega. Você percebe ali algo que aconteceu com ele e já te prepara para uma situação que pode vir futuramente. Acho que é muito produtivo. A gente percebe outra coisa tanto no sentido de conversar com outros professores quanto conversar com a turma. Não dá para ser professor se isolando não, tem que ter troca, interação. Eu achei aqui realmente um espírito coletivo: ajudar e se preocupar com o outro, dividir a forma de dá aula. (FESTA, DOCENTE DO IFPI).

Quando eu estou dando aula eu observo se a aula está sendo interessante. [...] Às vezes eu mudo o modo de dar aula em função da resposta da turma. Peço sugestão aos alunos para estudarmos coisas novas, além da ementa, para eles se interessarem. (VIDA, DOCENTE DO IFPI).

Fonte: dados da pesquisa (2020).

Depreende-se neste estudo que sob variadas formas, os professores citam as interações com os colegas mais experientes e com os alunos. Interações as quais se desenvolvem em ambientes institucionais ou onde se trate de temas relacionados ao 
processo pedagógico, construindo, a partir da experiência gerada por meio dessas relações, saberes que se mostram indispensáveis para a construção de suas identidades como professores da EPT.

A bagagem dos professores mais experientes apresenta-se como um parâmetro que referencia o início da trajetória na docência. Entende-se que é possível acessar o repertório de saberes oriundos da experiência docente durante as inter-relações vividas no grupo de trabalho, assim como participando de redes de aprendizagem por meio das tecnologias da informação e comunicação, como destacado pelo professor Força.

Esse compartilhamento de experiências pode acontecer de forma artesanal, na informalidade das interações cotidianas, ou formalmente, nas reuniões pedagógicas, nos eventos e nos espaços de formação, como afirma Tardif (2014).

Nas narrativas dos professores, ressai-se a relevância da relação que estabelecem com os alunos e o valor que esses sujeitos têm na constituição da identidade docente, o que Gariglio e Burnier (2014, p. 948) denominam de "eu profissional".

Os susoditos autores demonstram que o saber experiencial, construído no contexto da prática docente, parece estar relacionado a um tipo de aprendizagem fundamental à profissão: aquela realizada em uma rede de interações com outros sujeitos, em um cenário em que o elemento humano é determinante e composto por símbolos, valores, sentimentos e atitudes passíveis de interpretação e decisão.

Em virtude do que foi mencionado, entende-se que a principal ferramenta de construção dos saberes docentes ao longo da carreira dos professores bacharéis e tecnólogos da EPT é a experiência durante a prática docente. Os saberes docentes, com exceção dos disciplinares, são construídos partindo, inicialmente, da concepção prévia sobre o que é ser professor, trazida de suas experiências como estudantes durante a trajetória escolar, avançando para o aprendizado por meio da prática, assim como de interações com os professores mais experientes e do contato com os alunos. Logo, é na prática docente cotidiana, em confronto com as condições da profissão, que os saberes da base profissional se objetivam (GARIGLIO; BURNIER, 2014).

Em face do exposto, atina-se que os saberes experienciais, associados ao domínio do conhecimento técnico, são considerados pelos professores da EPT o 
repertório disponível mais importante para o exercício da docência. Os saberes pedagógicos apresentam-se como uma necessidade formativa dos professores, e devem ser ampliados não só por intermédio da experiência, mas de uma formação que tenha a prática como ponto de partida e chegada. Todos esses saberes são incorporados na experiência direta de ensino em sala de aula e no compartilhamento de experiências com outros professores.

\section{Considerações finais}

Esta investigação desenvolveu-se na perspectiva de discussão sobre a construção dos saberes docentes no processo de desenvolvimento profissional dos professores bacharéis e tecnólogos que compõem o quadro docente da EPT do IFPI.

O estudo evidenciou que os saberes docentes mobilizados pelos professores participantes da pesquisa trazem marcas do contexto do mercado de trabalho. Os participantes consideram que para exercer a docência na EPT, é necessário ter experiência do mercado na área em que se pretende ensinar.

Os dados mostraram que na relação entre o saber técnico oriundo do mercado de trabalho e as situações pedagógicas enfrentadas em sala de aula, os saberes docentes ganham sentido e validade, fornecendo aos profissionais segurança e embasamento para uma atuação docente mais efetiva.

Apesar da importância destinada ao saber técnico, os professores reconhecem o valor significativo que os saberes pedagógicos possuem para a atuação docente. Os dados revelaram que os participantes reconhecem que é fundamental possuir os saberes pedagógicos para que seja possível estabelecer estratégias de ensino adequadas às necessidades de aprendizagem dos alunos.

Também foi possível identificar que os participantes têm consciência de que não se pode ser professor com apenas uma categoria de saber: é preciso que haja interligação entre eles, pois é a partir da mobilização dos diversos saberes que o professor atinge uma prática docente promotora da aprendizagem significativa do aluno.

Partindo dessas reflexões, observou-se que os professores trazem consigo a preocupação em desenvolver os saberes pedagógicos, principalmente no que se refere 
à gestão da sala de aula, ao planejamento, à construção de metodologias de ensino e de material didático para as disciplinas lecionadas.

Sob a ótica das narrativas, infere-se que a principal fonte para a construção dos saberes docentes, adotada pelos participantes da pesquisa, especialmente no início da carreira, relaciona-se com a experiência da prática de ensino em sala de aula. Outra fonte para a construção de saberes da docência revelado nos dados foi a relação de trocas de experiências com os professores mais experientes e por meio do contato com os alunos durante o processo educacional.

Em virtude do que foi mencionado, entende-se que a principal ferramenta de construção dos saberes docentes ao longo da carreira dos professores bacharéis e tecnólogos da EPT é a experiência durante a prática docente no IFPI.

Os saberes docentes, com exceção dos disciplinares, constroem-se partindo, inicialmente, da concepção prévia sobre o que é ser professor, trazida das experiências enquanto estudantes durante a trajetória escolar, avançando para o aprendizado por meio da prática, assim como pelas interações com os professores mais experientes e do contato com os alunos. Dessarte, como defendido por Gariglio e Burnier (2014), é no enfretamento das condições da profissão que os saberes da base profissional docente se objetivam e continuamente se ressignificam.

As necessidades formativas demonstradas pelos professores durante as narrativas sinalizam para a exigência de implementação de programas de formação pedagógica docente, mediante a adoção de políticas institucionais de desenvolvimento profissional por parte do IFPI. Nessa perspectiva, sugerem-se cursos de formação continuada, com regularidade e em serviço, de modo que tomem como ponto de partida a relação com a prática reflexiva docente, os saberes necessários para o exercício da docência na EPT apontados nos estudos científicos e as necessidades formativas manifestadas pelos professores.

Nesse sentido, propõe-se um programa de desenvolvimento profissional docente que abranja todas as fases da carreira do professor, abarcando a formação teórica sobre os saberes da docência, em níveis adequados a cada fase do desenvolvimento profissional. O programa deve, ainda, fomentar a relação teoria e prática a partir da reflexão pautada nas experiências pedagógicas vivenciadas pelos professores, podendo ser compartilhado em pequenos grupos de estudo e discussão, 
o quais devem ser heterogêneos, integrados por professores em diversas fases da carreira. Além das discussões, esses pequenos grupos podem produzir novos saberes, a partir da análise das práticas pedagógicas partilhadas, gerando novas estratégias didáticas e novos projetos. É importante que cada grupo de docente interaja com outros grupos, formando uma rede de saberes.

Além das estratégias referidas, o programa pode promover aos docentes iniciantes uma relação de "tutoria" com professores mais experientes, a fim de que os docentes "tutelados" tenham acesso a orientações de colegas mais próximos e mais experientes. Isso porque acredita-se que no início da docência, as situações-problemas enfrentadas pelo professor iniciante são frequentes e nem sempre é possível ter acesso imediato a respostas por meio de formação continuada ou assessoria pedagógica institucional. Assim, o professor “tutor", que já enfrentou desafios semelhantes, pode suprir uma demanda imediata a partir do compartilhamento de ideias.

Diante disso, defende-se a necessidade de maior valorização dos saberes construídos pelos professores na ação docente, especialmente os da experiência, corroborando com Cunha (2007) quando diz que é preciso que os saberes gerados no cotidiano das salas de aula sejam sistematizados e socializados entre os docentes, a fim de permitir a busca de referenciais teóricos que lhes promovam o aprofundamento e diálogo reflexivo, baseado não somente na experiência individual, mas principalmente, na discussão coletiva.

Com a realização deste estudo, constatou-se que o processo de construção de saberes docentes possibilita suprir, em alguns casos, a deficiência de determinado saber necessário para a solução de situações pedagógicas. Entretanto, concebe-se que a atividade docente necessita ser fundamentada em bases sólidas e apoiada pela formação contínua.

À vista do exposto, ressalta-se o desejo de que as reflexões apresentadas no presente estudo possam se revelar como uma produção de conhecimento relevante, que de fato possa incentivar a implementação de políticas institucionais de profissionalização dos professores da EPT.

\section{Referências}

BARDIN, L. Análise de conteúdo. São Paulo: Edições 70, 2016. 
BRASIL. Lei no 11.892, de 29 de dezembro de 2008. Institui a Rede Federal de Educação Profissional, Científica e Tecnológica, cria os Institutos Federais de Educação, Ciência e Tecnologia. Disponível em: http://www.planalto.gov.br/ccivil_03/_ato20072010/2008/lei/111892.htm. Acesso em: 07 jun. 2017.

CLANDININ, D. J.; CONNELLY, F. M. Pesquisa narrativa: experiências e história na pesquisa qualitativa. 2. ed. Uberlândia: EDUFU, 2015.

CRESWELL, J. W.; CLARK, V. L. P. Pesquisa de métodos mistos. São Paulo: Penso, 2013.

CUNHA, E. R. Saberes docentes ou saberes dos professores. Revista Cocar, [s. l.], v. 1, n. 2, p. 31-39, jul./dez. 2007. Disponível em: https://paginas.uepa.br/seer/index.php/cocar/article/view/130. Acesso em: 29 maio 2019.

GARIGLIO, J. A.; BURNIER, S. L. Os professores da educação profissional: saberes e práticas. Cadernos de Pesquisa, v. 44, n. 154, p. 934-959, 2014. Disponível em: http://www.scielo.br/pdf/cp/v44n154/1980-5314-cp-44-154-00934.pdf. Acesso em: 30 maio 2019.

GAUTHIER, C. et al. Por uma teoria da pedagogia: pesquisas contemporâneas sobre o saber docente. Ijuí: UNIJUÍ, 2006.

GONÇALVES, E. M. R. Prática pedagógica na educação infantil e a construção de saberes docentes. 2016. Dissertação (Mestrado em Educação) - Universidade Federal do Piauí, Teresina, 2016. Disponível em: https://repositorio.ufpi.br/xmlui/handle/123456789/722. Acesso em: 03 fev. 2019.

HUBERMAN, M. O ciclo de vida profissional dos professores. In: NÓVOA, A. (org.). Vidas de professores. Porto: Porto Editora, 1995. p. 31-61.

JOVCHELOVITCH, S.; BAUER, M. W. Entrevista narrativa. In: Pesquisa qualitativa com texto, imagem e som: um manual prático. 13. ed. Petrópolis: Vozes, 2015. p. 90-113.

NÓVOA, A.; FINGER, M. (org.). O método (auto)biográfico e a formação. São Paulo: Paulus, 2010.

NUNES, C. M. F. Saberes docentes e formação de professores: um breve panorama da pesquisa brasileira. Educação \& Sociedade, ano 22, n. 74, abr. 2001.

NUNES, C. P. A identidade docente de bacharéis da rede federal de educação, ciência e tecnologia. Teresina: Garcia, 2016.

PIMENTA, S. G. (org.). Saberes pedagógicos e atividade docente. 8. ed. São Paulo: Cortez, 2012.

PORTELA, M. O. S. Docência no Ensino Superior: dilemas da prática pedagógica do professor bacharel em ciências contábeis da UFPI/Teresina. 2017. Dissertação (Mestrado em Educação) Universidade Federal do Piauí, Teresina, 2017. Disponível em: https://repositorio.ufpi.br/xmlui/handle/123456789/577. Acesso em: 25 jun. 2019.

PORTELA, M. O. S.; CARVALHÊDO, J. L. P. Contexto histórico da formação do professor bacharel em Ciências Contábeis para a docência no ensino superior e o desenvolvimento da profissionalidade docente. Linguagens, Educação e Sociedade, Teresina, ano 01, n. 2, p. 229-246, mai./ago. 2017. 
RAMIREZ, V. L. A constituição do profissionalismo docente e suas interfaces com o exercício da docência no Ensino Superior. Tese (Doutorado em Educação) - Faculdade de Educação, Pontifícia Universidade Católica do Rio Grande do Sul, Porto Alegre, 2011.

SCHÖN, D. A. Educando o profissional reflexivo: um novo design para o ensino e a aprendizagem. Tradução de Roberto Cataldo Costa. Porto Alegre: Artes Médicas Sul, 2000.

SHULMAN, L. S. Those who understand: Knowledge growth in teaching. Educational Researcher, v. 15, n. 2, p. 4-14, fev. 1986. Disponível em: http://links.jstor.org/ sici?sici=0013189X\%28198602\%2915\%3A2\%3C4\%3ATWUKGI\%3E2.0.CO\%3B2-X. Acesso em: 06 nov. 2007.

TARDIF, M. Saberes docentes e formação profissional. 17. ed. Rio de Janeiro: Vozes, 2014.

TARDIF, M.; LESSARD, C. O trabalho docente. 7. ed. Petrópolis, RJ: Vozes, 2012.

WARSCHAUER, C. A roda e o registro: uma parceria entre professor, alunos e conhecimento. Rio de Janeiro: Paz e Terra, 1993.

RECEBIDO: 09/07/2021

APROVADO: $14 / 10 / 2021$

RECEIVED: 07/09/2021

APPROVED: $10 / 14 / 2021$

RECIBIDO: 09/07/2021

APROBADO: $14 / 10 / 2021$ 